\title{
Thirty years of fatal familial insomnia and autonomic research: celebrating the past, embracing the future
}

\author{
Pietro Cortelli ${ }^{1}$
}

Received: 15 January 2021 / Accepted: 18 January 2021 / Published online: 3 February 2021

c) Springer-Verlag GmbH Germany, part of Springer Nature 2021

Keywords Fatal familial insomnia $\cdot$ Agrypnia excitata $\cdot$ Sleep disorders $\cdot$ Dysautonomia $\cdot$ Cardiovascular $\cdot$ Sympathetic

Thirty years have passed since the publication of the first issue of Clinical Autonomic Research, a much-loved journal in which I had the honor and pleasure of being the first author of a paper [1] that would later prove to be crucial for my scientific and academic career. More moving and dear to me are the memories of the meetings of the now-extinct Clinical Autonomic Research Society that took place for the first time in a grey London in the autumn of 1982. These meetings were hosted by the University College of London Queen Square Institute of Neurology and brought together a small group of predominantly clinical scientists, each very active in their field, with a keen interest in the latest findings of preclinical science and a restless scientific curiosity. It was this group of passionate scientists, who quickly became close friends, that laid the foundations necessary to start and share this magnificent adventure.

Those gatherings were a true scientific arena where every presentation was discussed in such depth and detail, that by the time a study passed that test it was ready to be submitted for publication. I still have fond memories of the presentation I gave, I believe in the autumn of 1988, on the autonomic control of the cardiovascular system in the first patient with fatal familial insomnia. I can still see in my mind the skeptical faces of those present when I showed that these patients could not sleep for months, and I remember the difficult and sharp questions that followed my presentation posed by Otto Appenzeller, Christopher Mathias, and Ron Polinsky. Overall, I managed to pass this test fairly well and I was very pleased when, at the end of the day in front of a beer, the maestri encouraged me to publish this data.

Pietro Cortelli

pietro.cortelli@unibo.it

1 Institute of Neurological Sciences of Bologna, IRCCS Istituto delle Scienze Neurologiche di Bologna, University of Bologna, via Altura 3, 40139 Bologna, Italy
Great! But where to submit a scientific article that dealt with the clinical problems related to disorder affecting both sleep and the autonomic nervous system? This was a problem, because at the time, autonomic medicine was the "Cinderella" of neurology and other medical specialties practically ignored its role and existence. Consequently, the five or six international neurology journals of that time were seldom interested in publishing studies dealing with autonomic issues. And so, it was in those years, under the aegis of Sir Roger Bannister and the driving force of Christopher Mathias, that the idea a journal entirely dedicated to the fascinating field of autonomic medicine was developed.

The journal's motto at that time- - An international journal for fast communications of research and treatment related to autonomic function and dysfunction"- captured perfectly the aim of the journal. Today, we can say that the gamble has paid off and we proudly see our Clinical Autonomic Research journal growing in scientific weight every year. However, most importantly we see young, brilliant autonomic scientists publishing high-quality manuscripts in Clinical Autonomic Research and involved in its editorial board. Not only does this mean that we took the right path at the time, but that we are now running at the necessary speed to be competitive in this era, so different from our own time when I was used to creating my slides first on paper and then took them to the photographer at least a week before the presentation!

As I said, my contribution to the first issue of Clinical Autonomic Research was an important moment for me as I was the first to explain a phenomenon that, until then, no one had described: a persistent deprivation of slow-wave sleep that eventually led to death. This was associated with atrophy of the dorsomedial and anterior nuclei of the thalamus, which were believed to be largely connected to memory. My mentors, Prof. Elio Lugaresi [2] and Prof. Montagna [3] were the first ones to identify this disorder, which they 
baptized as fatal familial insomnia [4]. They advised me to study in-depth the autonomic function of these patients to understand the pathophysiology of this disorder (Fig. 1a). It was they who encouraged me to present the results at the Queen Square Institute of Neurology in London. The focus of my manuscript published in Clinical Autonomic Research was the description of the cardiovascular autonomic control with biochemical and pharmacological techniques in two patients with fatal familial insomnia. We were able to prove, for the first time, that these patients had a dramatically increased sympathetic tone with a normal parasympathetic tone.

The following decade was a period full of discoveries for fatal familial insomnia. We discovered its genetic cause $[5,6]$ and we characterized the prion protein involved in the disorder [7]. Our breakthroughs helped Stanley Prusiner in his work on prions [8], awarded with a muchdeserved Nobel Prize in 1997, as well as the definition of the role of the medial thalamus in the central autonomic network $[9,10]$. From a pathophysiology perspective, our initial hunch that an excessive sympathetic tone was both cause and effect of the severe slow-wave sleep deprivation has been confirmed, and is the rationale to swap the ambiguous and misleading "insomnia" with "agrypnia excitata" (agrypnia—wakefulness in Greek; and excitataexcited in Latin, in reference to the permanent motor and autonomic hyperactivation in these patients) [11].

Finally, I fondly remember my friends from the meetings of the Clinical Autonomic Research Society. This club never stopped, and eventually, despite the painful bureaucracy involved, succeeded in morphing into the European Federation of Autonomic Societies (EFAS) that, together with its sister organization, the American Autonomic Society (AAS), brought to life a series of memorable conferences in Bologna in 1999 (Fig. 1b), London in 2001, Athens in 2002 (Fig. 1c), Toulouse in 2003, Amsterdam in 2004, Bled in 2005, Lisbon in 2006, Wien in 2007, and Naxos in 2010.
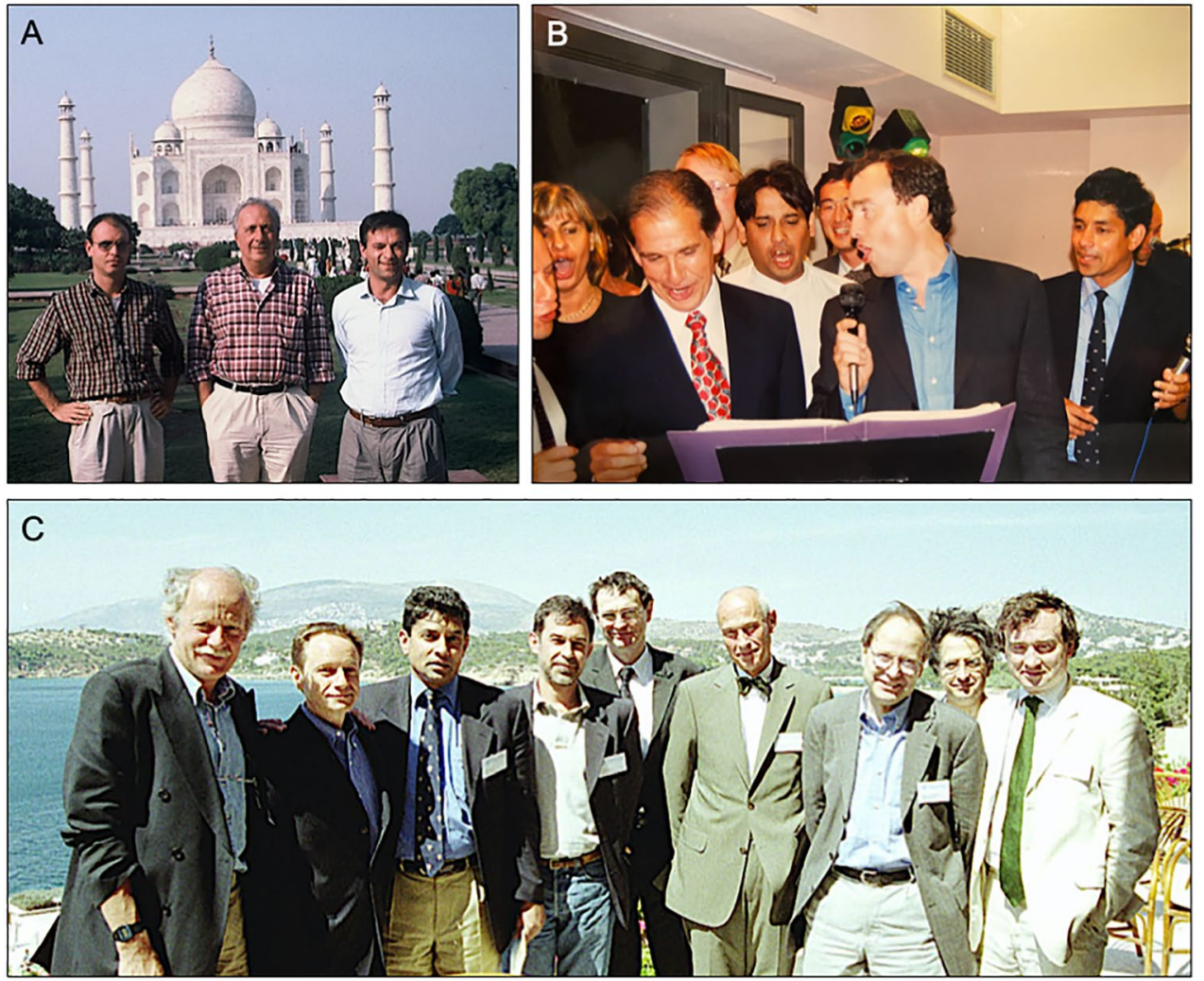

Fig. 1 a A moment of relax visiting the Taj Mahal after the 14th World Congress of Neurology in 1989 that took place in New Delhi (India), where we had a fantastic dinner with Christopher Mathias. Between a delicacy and another, we agreed on the need to have a scientific journal dedicated to clinical aspects related to autonomic medicine and Prof. Lugaresi officially agreed to join the editorial board of Clinical Autonomic Research. From left to right: Prof. Pasquale Montagna, Prof. Elio Lugaresi, and the author (Pietro Cortelli). b The gala dinner at the first EFAS meeting in Bologna (Italy) in 1999 was followed by a memorable karaoke with an "Autonomic Quintet". From left to right: Eduardo Benarroch, K. Ray Chaudhury, Tetsutaro Ozawa, Oliver Foster, and Christopher Mathias. c Group photo after a "strenuous" council of the European Federation of Autonomic Societies (EFAS) in Athens (Greece) in 2002. From left to right: Wouter Wieling, Horacio Kaufmann, Christopher Mathias, Jean-Michel Senard, Max Hilz, Thomas Thiekötter (managing director of Springer at the time), Bernhard Neundörfer, José Luís Ducla-Soares, and Oliver Foster 
After 30 years, the study of the autonomic nervous system has become key to our understanding of the mechanisms of many neurological, sleep, and cardiovascular disorders. Today, knowing if a patient with motor signs of Parkinson disease also has orthostatic hypotension is vital in providing a correct prognosis and treatment. In contrast, blood pressure measurements were rarely taken decades ago, and certainly never while standing.

Despite the awareness that a lot has been achieved, it is also evident that there is still a lot to do. In particular, a lot more must be done with the education of students to widen their knowledge of the autonomic nervous system. We must encourage the dissemination of an ethos that interprets health as the result of the integrated function of the somatic and autonomic systems, and the delicate balance between the parasympathetic function of energy conservation and the sympathetic function of energy expenditure. This will result in the research of all-encompassing treatments that challenge the old concept of the illness affecting a single organ. It is also the time to consolidate in the mind of our students the concept of "allostasis" compared to the simpler and more famous "homeostasis." The former has helped us to understand different phenomena such as the transition from nocturnal hypertension to chronic, fixed hypertension in patients with obstructive sleep apnea syndrome [12] or the transformation of episodic migraine into the more fearsome chronic form [13, 14].

Clinical Autonomic Research has been the means for the global dissemination of this extraordinary cultural path that began back in that small lecture hall at the University College of London Queen Square Institute of Neurology, and that, I am sure, will also surprise us with its achievements in the future. Please, join me in raising a glass of good Italian wine to cheer Clinical Autonomic Research for a long life full of the successes our journal so deserves!

Funding None.

\section{Compliance with ethical standards}

Conflict of interest The authors declared that they have no conflict of interest.

\section{References}

1. Cortelli P, Parchi P, Contin M, Pierangeli G, Avoni P, Tinuper P, Montagna P, Baruzzi A, Gambetti PL, Lugaresi E (1991)
Cardiovascular dysautonomia in fatal familial insomnia. Clin Auton Res 1(1):15-21

2. In Memoriam of Elio Lugaresi, MD (1926-2015) Agostino Baruzzi, Fabio Cirignotta, Pietro Cortelli, Rocco Liguori, Giuseppe Plazzi, Federica Provini, Paolo Tinuper. (2016) Neurology 86 (23): 2124-2125

3. In Memoriam of Pasquale Montagna, MD (1950-2010) Sudhansu Chokroverty, Antonio Culebras, Elio Lugaresi (2011) Neurology. 76 (19): 1616

4. Lugaresi E, Medori R, Montagna P, Baruzzi A, Cortelli P, Lugaresi A, Tinuper P, Zucconi M, Gambetti P (1986) Fatal familial insomnia and dysautonomia with selective degeneration of thalamic nuclei. N Engl J Med 315(16):997-1003

5. Medori R, Tritschler HJ, LeBlanc A, Villare F, Manetto V, Chen HY, Xue R, Leal S, Montagna P, Cortelli P et al (1992) Fatal familial insomnia, a prion disease with a mutation at codon 178 of the prion protein gene. N Engl J Med 326(7):444-449

6. Goldfarb LG, Petersen RB, Tabaton M, Brown P, LeBlanc AC, Montagna P, Cortelli P, Julien J, Vital C, Pendelbury WW et al (1992) Fatal familial insomnia and familial Creutzfeldt-Jakob disease: disease phenotype determined by a DNA polymorphism. Science 258(5083):806-808

7. Monari L, Chen SG, Brown P, Parchi P, Petersen RB, Mikol J, Gray F, Cortelli P, Montagna P, Ghetti B et al (1994) Fatal familial insomnia and familial Creutzfeldt-Jakob disease: different prion proteins determined by a DNA polymorphism. Proc Natl Acad Sci USA 91(7):2839-2842

8. Telling GC, Parchi P, DeArmond SJ, Cortelli P, Montagna P, Gabizon R, Mastrianni J, Lugaresi E, Gambetti P, Prusiner SB (1996) Evidence for the conformation of the pathologic isoform of the prion protein enciphering and propagating prion diversity. Science 274(5295):2079-2082

9. Lugaresi E, Tobler I, Gambetti P, Montagna P (1998) The pathophysiology of fatal familial insomnia. Brain Pathol 8(3):521-526

10. Benarroch EE, Stotz-Potter EH (1998) Dysautonomia in fatal familial insomnia as an indicator of the potential role of the thalamus in autonomic control. Brain Pathol 8(3):527-530

11. Baldelli L, Provini F (2019) Fatal familial insomnia and Agrypnia Excitata: autonomic dysfunctions and pathophysiological implications. Auton Neurosci 218:68-86

12. Cortelli P, Parchi P, Sforza E, Contin M, Pierangeli G, Barletta G, Lugaresi E (1994) Cardiovascular autonomic dysfunction in normotensive awake subjects with obstructive sleep apnoea syndrome. Clin Auton Res 4(1-2):57-62

13. Cortelli P, Pierangeli G, Montagna $P$ (2010) Is migraine a disease? Neurol Sci 31(Suppl 1):S29-31

14. Borsook D, Maleki N, Becerra L, McEwen B (2012) Understanding migraine through the lens of maladaptive stress responses: a model disease of allostatic load. Neuron 73(2):219-234 